\title{
EFEKTIFITAS MODUL BASIC AIRWAY MANAGEMENT BERBASIS GUIDED INQUIRY LEARNING MODEL TERHADAP KETERAMPILAN MAHASISWA KEPERAWATAN
}

\author{
Maria Wisnu Kanita ${ }^{1)}$, Ika Subekti Wulandari ${ }^{2)}$, Gatot Suparmanto ${ }^{3)}$, Heni Nur \\ Kusumawati $^{4)}$ \\ 1,2,3 Universitas Kusuma Husada Surakarta, ${ }^{4}$ Poltekkes Kemenkes Surakarta \\ mariaw@ukh.ac.id
}

\begin{abstract}
ABSTRAK
Pembelajaran dalam praktik klinik merupakan komponen penting dalam pendidikan keperawatan mengingat keperawatan merupakan profesi berbasis praktik. Pembelajaran praktik klinik oleh mahasiswa keperawatan memerlukan adanya pengembangan metode yang dapat mempersiapkan mahasiswa untuk dapat mengasah keterampilannya. Tujuan penelitian ini adalah untuk mengetahui efektifitas modul basic airway management berbasis guided inquiry learning model terhadap keterampilan mahasiswa keperawatan. Penelitian ini adalah penelitian kuantitatif dengan quasi experimental dalam bentuk nonequivalent pretes-postest group design. 50 responden dipilih dengan teknik purposive sampling, 25 responden pada kelompok eksperimen, sedangkan 25 responden pada kelompok kontrol. Keterampilan sebelum perlakuan pada kelompok kontrol dinyatakan lulus sebanyak 3 responden (12\%) dan kelompok intervensi sebanyak 6 responden (24\%). Keterampilan setelah dilakukan perlakuan pada kelompok kontrol dinyatakan lulus sebanyak 11 responden (44\%) dan kelompok intervensi sebanyak 15 responden (66\%).

Data dalam penelitian dianalisis dengan uji Mann-Whitney. Hasil uji menunjukkan nilai $\mathrm{p}$ $=0,000$ dimana hasil ini menyatakan bahwa Modul Berbasis Guided Inquiry Learning Model cukup efektif untuk meningkatkan keterampilan mahasiswa.
\end{abstract}

Kata kunci: basic airway management, guided inquiry learning model, modul

\begin{abstract}
Learning in clinical practice is an important component in nursing education considering that it is a practice-based profession. Learning clinical practice by students requires the development of methods that can prepare students to hone their skills. The purpose of this study was to determine the effectiveness of the basic airway management module based on the guided inquiry learning model on the skills of students. This study was a quantitative study with a quasi-experimental form of nonequivalent pretest-posttest group design. 50 respondents were selected by purposive sampling technique, 25 respondents were in the experimental group, while 25 respondents were in the control group. Before receiving the treatments, 3 respondents (12\%) in the control group and 6 respondents (24\%) were passed the skills. After receiving the treatment, as many as 11 respondents $(44 \%)$ in the control group and 15 respondents (66\%) the intervention group could pass the skills. The data in the study were analyzed by the Mann-Whitney test. The test results showed the value of $p=0.000$ which stated that the Guided Inquiry Learning ModelBased Module is quite effective for improving student skills.
\end{abstract}

Keywords: basic airway management, guided inquiry learning model, module

\section{PENDAHULUAN}

Pendidikan keperawatan dianggap memiliki kesenjangan antara teori dan praktik yang telah lama dianggap kontroversial. Hal tersebut terjadi karena adanya disparitas antara teori dan praktik dalam pendidikan keperawatan (Dlamini, 2011).

Pembelajaran dalam praktik klinik merupakan komponen penting dalam pendidikan keperawatan mengingat keperawatan merupakan profesi berbasis praktik (Kaphagawani \& Useh, 
2017). Pembelajaran praktik dapat membantu mahasiswa keperawatan untuk dapat menilai karakteristik lingkungan praktik. Hal tersebut dapat memberikan wawasan yang berguna untuk pengembangan ilmu yang dimiliki mahasiswa keperawatan (Henderson, 2012).

Ada kebutuhan untuk menggunakan strategi pembelajaran yang dapat memfasilitasi pembelajaran praktik untuk menciptakan lingkungan belajar klinis yang kondusif (Kaphagawani \& Useh, 2017). Pembelajaran praktik klinik oleh mahasiswa keperawatan memerlukan adanya pengembangan metode yang dapat mengasah keterampilan mahasiswa. Studi menyatakan bahwa dengan adanya kesempatan dari mahasiswa untuk mendapatkan metode pembelajaran yang sesuai, maka akan dapat mendukung mahasiswa dalam proses pembelajaran klinik (Chuana \& Barnett, 2012).

Pembelajaran klinik yang efektif memerlukan integrasi mahasiswa keperawatan ke dalam kegiatan praktik dan pendekatan pengajaran yang inovatif. Hal tersebut dilakukan untuk dapat memenuhi kebutuhan belajar individu mahasiswa (Henderson, 2012). Studi mengungkapkan bahwa pembelajaran yang efektif terjadi apabila dalam pembelajaran klinis mahasiswa keperawatan diberi kesempatan untuk mempraktikkan apa yang telah mereka pelajari di kelas dan laboratorium dengan cara diawasi dan didukung dan juga diberikan umpan balik dengan hubungan interpersonal dan komunikasi yang baik (Kaphagawani \& Useh, 2017).

Mahasiswa keperawatan perlu untuk mengasah kemampuannya dalam melakukan tindakan di laboratorium. Studi menyatakan untuk dapat meningkatkan pembelajaran di laboratorium, perlu adanya lingkungan yang otentik, adanya motivasi, dan adanya sumber daya untuk berbagai metode dan melatih keterampilan klinis secara berulang (Haraldseid, Friberg \& Aase, 2015).
Metode yang dapat digunakan untuk dapat menanamkan berbagai keterampilan tersebut yaitu melalui penerapan pembelajaran yang berorientasi kepada siswa (studentoriented learning) (Llewellyn, 2013). Pembelajaran yang berorientasi kepada siswa memiliki karakteristik melibatkan siswa secara aktif dalam pembelajaran (Remziye et al., 2011).

Model pembelajaran yang dapat diterapkan salah satunya adalah model pembelajaran inkuiri. Salah satu model pembelajaran inkuiri yang efektif digunakan yaitu Guided Inquiry Learning. Guided Inquiry Learning memberikan kesempatan kepada peserta didik untuk belajar secara aktif mengembangkan kemampuan berpikir secara sistematis, logis dan kritis sehingga peserta didik mampu menemukan konsep-konsep secara mandiri melalui pertanyaan yang diajukan (Hasibuan \& Andromeda, 2021). Studi menyatakan bahwa modul yang dikembangkan dengan Guided Inquiry Learning Model dapat efektif meningkatkan keterampilan siswa dan juga meningkatkan hasil belajar siswa (Dewi et al., 2017; Hasibuan \& Andromeda, 2021).

Mahasiswa keperawatan dituntut untuk dapat melakukan tindakan secara cepat terutama di area Keperawatan Gawat Darurat. Di lingkungan rumah sakit, pasien dapat memburuk dengan cepat sehingga mempertahankan pernapasan pasien adalah prioritas utama dalam setiap situasi darurat. Mahasiswa keperawatan nantinya akan menjadi tenaga kesehatan profesional sehingga harus mampu melakukan manajemen jalan napas dengan aman melalui penilaian yang menyeluruh terlebih dahulu untuk memastikan apakah jalan napas paten atau tidak, atau dengan melakukan basic airway management (Higginson, Jones \& Davies, 2010; Higginson, Parry \& Williams, 2016).

Pengetahuan yang tidak memadai tentang prinsip penanganan di kalangan profesional kesehatan mempengaruhi dalam penanganan darurat yang 
mendesak

(Nambiar,

Nedungalaparambil, \& Aslesh, 2016).

Sehingga dalam proses pembelajaran praktik, mahasiswa keperawatan diharapkan dapat menggunakan suatu pendekatan metode yang sesuai untuk dapat memaksimalkan pengetahuan dan keterampilan yang akan diperoleh oleh mahasiswa.

Studi pendahuluan mendapatkan hasil bahwa selama pembelajaran praktik yang telah dilakukan oleh mahasiswa hanya menggunakan lembar prosedur tindakan. Selebih itu mahasiswa mencari informasi secara mandiri dari handout ataupun buku teori.

Berdasarkan alasan-alasan yang telah dipaparkan dan melihat keberhasilan Guided Inquiry Learning Model sebelumnya, dirasa penting untuk mengetahui efektivitas dari modul yang dirancang berdasarkan Guided Inquiry Learning Model untuk mengukur psikomotor mahasiswa keperawatan dalam melakukan basic airway management.

\section{METODE PENELITIAN}

Penelitian ini adalah penelitian kuantitatif dengan desain penelitian yang digunakan adalah quasi experimental design dalam bentuk nonequivalent pretes-postest group design. Desain ini digunakan untuk melihat perbandingan mahasiswa keperawatan setelah pembelajaran dan sebelum pembelajaran antara kelompok eksperimen dan kelompok kontrol yang dipilih menggunakan teknik purposive sampling dengan kriteria inklusi mahasiswa keperawatan di Surakarta yang telah lulus perkuliahan pra syarat Mata Kuliah Keperawatan Gawat Darurat dan berkenan untuk menjadi responden dengan menandatangani informed consent penelitian. 25 responden pada kelompok eksperimen diberikan Modul Basic Airway Management Berbasis Guided Inquiry Learning Model, sedangkan 25 responden pada kelompok kontrol menggunakan media pembelajaran konvensional dengan handout Basic
Airway Management. Tidak ada drop out dalam penelitian dari responden yang telah bersedia. Peneliti merencanakan proses penelitian dilangsungkan secara tatap muka. Tetapi pada saat proses pengambilan data, pemerintah memberlakukan kebijakan pembatasan aktivitas akibat pandemi covid-19, sehingga pengambilan data dilakukan dengan cara daring. Responden diberikan waktu selama 1 minggu setelah dilakukan pretest untuk dapat mempelajari modul, setelah itu dilakukan posttest. Penilaian Basic Airway Management menggunakan lembar observasi keterampilan Basic Airway Management. Data dalam penelitian diperoleh melalui penilaian keterampilan basic airway management dengan menggunakan lembar observasi yang kemudian dianalisis dengan uji Mann-Whitney. Penelitian juga telah dinyatakan lolos uji etik KEPK RSDM.

\section{HASIL DAN PEMBAHASAN}

Uji efektivitas modul dilakukan terhadap dua kelompok yakni kelompok eksperimen dan kelompok kontrol. Kelompok eksperimen menggunakan Modul Basic Airway Management Berbasis Guided Inquiry Learning Model. Sementara itu kelompok kontrol menggunakan media pembelajaran konvensional yang biasa digunakan oleh mahasiswa dalam pembelajaran dengan handout.

Table 1. Distribusi frekuensi keterampilan basic airway management sebelum perlakuan $(n=50)$

\begin{tabular}{|c|c|c|c|c|c|c|}
\hline \multirow[t]{2}{*}{ Kelompok } & \multicolumn{2}{|c|}{ Lulus } & \multicolumn{2}{|c|}{$\begin{array}{l}\text { Tidak } \\
\text { lulus }\end{array}$} & \multicolumn{2}{|c|}{ Total } \\
\hline & f & $\%$ & f & $\%$ & $\mathrm{n}$ & $\%$ \\
\hline Kontrol & 3 & 12,0 & 22 & 88,0 & 25 & 100 \\
\hline Intervensi & 6 & 24,0 & 19 & 76,0 & 25 & 100 \\
\hline \multicolumn{7}{|c|}{$\begin{array}{l}\text { Sumber: Data primer, } 2021 \\
\quad \text { Berdasarkan hasil pretest pada kedua } \\
\text { kelompok, mayoritas responden tidak } \\
\text { lulus dalam keterampilan basic airway } \\
\text { management dengan nilai tertinggi ada } \\
\text { pada kelompok kontrol sebanyak } 22 \\
\text { orang }(88 \%) \text {. }\end{array}$} \\
\hline
\end{tabular}


Pembelajaran praktik dapat membantu mahasiswa keperawatan untuk dapat menilai karakteristik lingkungan praktik. Hal tersebut dapat memberikan wawasan yang berguna untuk pengembangan ilmu yang dimiliki mahasiswa keperawatan (Henderson, 2012). Pada hasil pretest tampak responden memiliki kecenderungan kurang mampu memenuhi nilai lulus dari keterampilan basic airway management. Mahasiswa memerlukan pengalaman untuk dapat melakukan tindakan di lingkungan yang memiliki kemiripan dengan lahan klinik seperti di laboratorium. Sehingga mahasiswa akan dapat melatih keterampilan klinis secara berulang dan mengasah kemampuannya dalam melakukan tindakan (Haraldseid, Friberg \& Aase, 2015).

Table 2. Distribusi frekuensi keterampilan basic airway management setelah perlakuan $(n=50)$

\begin{tabular}{lcccccc}
\hline Kelompok & \multicolumn{2}{c}{ Lulus } & \multicolumn{2}{c}{ Tidak } & \multicolumn{2}{c}{ Total } \\
& \multicolumn{1}{c}{ lulus } \\
& f & \% & f & \% & n & \% \\
\hline Kontrol & 11 & 44,0 & 14 & 56,0 & 25 & 100 \\
\hline Intervensi & 15 & 60,0 & 10 & 40,0 & 25 & 100
\end{tabular}

Sumber: Data primer, 2021

Berdasarkan hasil posttest pada kedua kelompok didapatkan hasil bahwa kelompok intervensi yaitu dengan Modul Berbasis Guided Inquiry Learning Model dominan lulus dengan sejumlah 15 orang $(60 \%)$.

Pembelajaran praktik di laboratorium telah menjadi struktur penting dalam pendidikan perawat. Manfaat dari adanya pembelajaran di laboratorium telah diidentifikasi penggunaannya. Namun, masih diperlukan adanya identifikasi kebutuhan terkait dengan kesiapan mahasiswa dalam melakukan tindakan saat di kenyaataan praktik (Houghton et al., 2012).

Hasil penelitian menyatakan bahwa dengan adanya pemberian pembelajaran praktik di laboratorium dapat berdampak ke mahasiswa. Penggunaan strategi pembelajaran yang dapat memfasilitasi pembelajaran praktik untuk menciptakan lingkungan belajar klinis yang kondusif mutlak diperlukan (Kaphagawani \& Useh, 2017). Pembelajaran praktik klinik oleh mahasiswa keperawatan memerlukan adanya pengembangan metode yang dapat mengasah keterampilan mahasiswa. Studi menyatakan bahwa dengan adanya kesempatan dari mahasiswa untuk mendapatkan metode pembelajaran yang sesuai, maka akan dapat mendukung mahasiswa dalam proses pembelajaran klinik (Chuana \& Barnett, 2012).

Tabel 3. Uji normalitas data keterampilan basic airway management $(\mathrm{n}=50)$

\begin{tabular}{lcc}
\hline Kelompok & \multicolumn{2}{c}{ Shapiro wilk } \\
\cline { 2 - 3 } & n & p-value \\
\hline Kontrol & 25 & 0,000 \\
\hline Intervensi & 25 & 0,000 \\
\hline Uji normalitas data & kelompok \\
kontrol dan kelompok intervensi \\
menggunakan Shapiro-Wilk. Hasil uji \\
normalitas data didapatkan p-value = \\
0,000 artinya bahwa data tersebut \\
berdistribusi tidak normal, sehingga \\
menggunakan uji analisis Mann- \\
Whitney.
\end{tabular}

Tabel 4. Efektifitas Modul Berbasis Guided Inquiry Learning Model terhadap Keterampilan Basic Airway Management

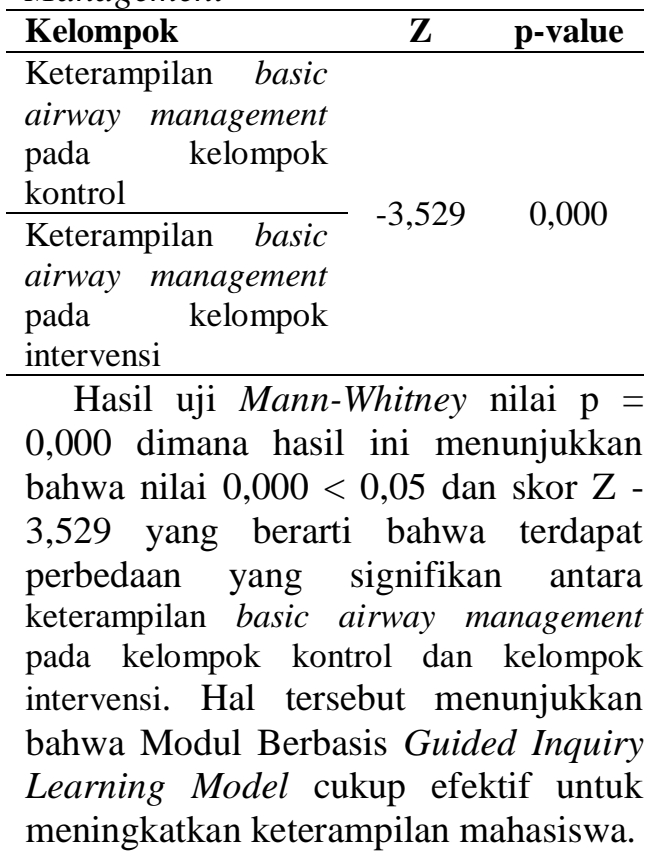


Pembelajaran keterampilan klinis dapat menyediakan mahasiswa untuk dapat berlatih dalam melakukan tindakan. Strategi pengajaran perlu dipertimbangkan dalam proses pembelajaran (Houghton et al., 2012).

Salah satu cara yang dapat digunakan dalam proses pembelajaran praktik adalah model pembelajaran Inquiry. Salah satu model pembelajaran inkuiri yang efektif digunakan yaitu Guided Inquiry Learning. Penelitian ini menggunakan Modul berbasis Guided Inquiry Learning Model, dengan penggunaan modul ini hasil penelitian menyatakan bahwa modul ini lebih efektif untuk meningkatkan keterampilan mahasiswa. Guided Inquiry Learning memiliki kelebihan untuk dapat memberikan kesempatan kepada peserta didik untuk belajar secara aktif mengembangkan kemampuan berpikir secara sistematis, logis dan kritis sehingga peserta didik mampu menemukan konsep-konsep secara mandiri melalui pertanyaan yang diajukan (Hasibuan \& Andromeda, 2021). Hasil studi lain mendukung dari hasil penelitian ini dimana studi lain menyatakan bahwa modul yang dikembangkan dengan Guided Inquiry Learning Model dapat efektif meningkatkan keterampilan siswa dan juga meningkatkan hasil belajar siswa (Dewi et al., 2017; Hasibuan \& Andromeda, 2021).

Proses pembelajaran keperawatan harus dapat membawa mahasiswa untuk bersiap secara memadai untuk lingkungan klinis di kehidupan nyata (Houghton et al., 2013). Studi mengungkapkan bahwa pembelajaran yang efektif terjadi apabila dalam pembelajaran klinis mahasiswa keperawatan diberi kesempatan untuk mempraktikkan apa yang telah mereka pelajari di kelas dan laboratorium dengan cara diawasi dan didukung dan juga diberikan umpan balik dengan hubungan interpersonal dan komunikasi yang baik (Kaphagawani \& Useh, 2017).

Penelitian ini menggunakan Modul berbasis Guided Inquiry Learning
Model yang dapat membantu mahasiswa untuk dapat menumbuhkan proses berpikir dan menganalisa mahasiswa. Hal tersebut didukung oleh studi terdahulu yang juga menyatakan bahwa inkuiri yang memiliki kelebuhan dapat menumbuhkan keterampilan proses sains (Nworgu \& Otum, 2013; Rizal, 2014). Hasil penelitian lain juga menyatakan bahwa Modul Guided Inquiry Learning Model ini dapat mengembangkan model inkuiri yang meliputi keterampilan proses yang meliputi pengamatan, mengumpulkan dan mengorganisasi data, mengidentifikasi dan mengontrol variabel, menguji dan merumuskan hipotesis, keterampilan menjelaskan dan inferensi. Aktifitas pembelajaran dengan menggunakan inkuiri terbimbing membantu mahasiswa untuk mengembangkan rasa tanggung jawab individu, metode kognitif, pembuatan laporan, penyelesaian masalah, dan kemampuan memahami (Dewi et al., 2017).

Pengembangan Modul berbasis Guided Inquiry Learning Model akan dapat membantu mahasiswa dalam proses melewati proses belajar dari Mata Kuliah Keperawatan Gawat Darurat. Mahasiswa keperawatan dituntut untuk dapat melakukan tindakan secara cepat terutama di area Keperawatan Gawat Darurat Pernafasan. Di lingkungan rumah sakit, pasien dapat memburuk dengan cepat sehingga mempertahankan pernapasan pasien adalah prioritas utama dalam setiap situasi darurat (Nambiar, Nedungalaparambil, \& Aslesh, 2016).

Mahasiswa keperawatan nantinya akan menjadi tenaga kesehatan profesional sehingga harus mampu melakukan manajemen jalan napas dengan aman melalui penilaian yang menyeluruh terlebih dahulu untuk memastikan apakah jalan napas paten atau tidak, atau dengan melakukan basic airway management (Higginson, Jones \& Davies, 2010; Higginson, Parry \& Williams, 2016). Dengan adanya model yang sesuai untuk pembelajaran mahasiswa terutama di pratik, dapat 
mendukung mahasiswa untuk mengembangkan kepercayaan diri dan memastikan bahwa mahasiswa siap karena telah memiliki pengalaman sebelumnya dalam melakukan keterampilan klinis (Houghton et al., 2013)

\section{KESIMPULAN}

Keterampilan sebelum perlakuan pada kelompok kontrol dinyatakan lulus sebanyak 3 responden $(12 \%)$ dan kelompok intervensi sebanyak 6 responden $(24 \%)$. Keterampilan setelah dilakukan perlakuan pada kelompok kontrol dinyatakan lulus sebanyak 11 responden (44\%) dan kelompok intervensi sebanyak 15 responden (66\%). Hasil uji Mann-Whitney menunjukkan nilai $\mathrm{p}=0,000$ dimana hasil ini menyatakan bahwa Modul Berbasis Guided Inquiry Learning Model cukup efektif untuk meningkatkan keterampilan mahasiswa.

\section{SARAN}

Pembelajaran keterampilan klinis dapat memberikan kesempatan kepada mahasiswa keperawatan untuk dapat berlatih dan memiliki pengalaman sebelum melakukan di area praktik. Pengembangan strategi pembelajaran keterampilan klinis perlu dipertimbangkan dalam proses pembelajaran agar mahasiswa dapat mencapai hasil yang maksimal.

\section{UCAPAN TERIMA KASIH}

Penulis ucapan terima kasih kepada pihak-pihak yang mendukung penulisan artikel ini antara lain Universitas Kusuma Husada Surakarta atas dukungan dana hibah internal dan Partisipan penelitian yang senantiasa memberikan respon yang baik untuk terlaksananya penelitian ini, serta pihak-pihak terkait dalam penelitian.

\section{REFERENSI}

Chuana, O.L. dan Barnett, T. (2012) Student, tutor and staff nurse perceptions of the clinical learning environment, Nurse Education in
Practice Journal, 12(4), p 192-197, doi:

https://doi.org/10.1016/j.nepr.2012.01 .003

Dewi, E.P., Suyatna, A., Abdurrahman, dan Ertikanto, C. (2017) Efektivitas Modul dengan Model Inkuiri untuk Menumbuhkan Keterampilan Proses Sains Siswa pada Materi Kalor, Journal of Education and Teacher Training, 2(2), doi: https://doi.org/10.24042/tadris.v2i2.19 $\underline{01}$

Dlamini, C.P. (2011) Perceptions of Students and Nurse Educators on the Integration of Theory and Practice in Nursing Education in Swaziland: An Exploratory- Descriptive Study, Dissertation, Available at: https://researchspace.ukzn.ac.za/handl e/10413/4722

Haraldseid, C., Friberg, F., dan Aase, K. (2015) Nursing students' perceptions of factors influencing their learning environment in a clinical skills laboratory: A qualitative study, Nurse Education Today Journal, 35(9), p e1e6, doi: https://doi.org/10.1016/j.nedt.2015.03. $\underline{015}$

Hasibuan, S.R, dan Andromeda (2021) Efektivitas Penggunaan E-Modul Sistem Koloid Berbasis Inkuiri Terbimbing Terintegrasi Laboratorium Virtual Terhadap Hasil Belajar Peserta Didik Kelas XI SMAS Nurul 'Ilmi, Journal of Multidicsiplinary Research and Development, 3(2), p 7 - 12, doi: https://doi.org/10.31933/rri.v3i2.364

Henderson, A., et. al. (2012) Nursing students' perceptions of learning in practice environments: A review, Nurse Education Today Journal, 32(3), p 299-302, doi: https://doi.org/10.1016/j.nedt.2011.03. $\underline{010}$

Higginson, R., Jones, B., dan Davies, K. (2010) Airway management for nurses: emergency assessment and 
care, British Journal of Nursing, 19(16), p 1006-1014. doi: https://doi.org/10.12968/bjon.2010.19 .16 .78185 .

Higginson, R., Parry, A., dan Williams, M., (2016) Airway management in the hospital environment, British Journal of Nursing, 25(2), p 94-100, doi: https://doi.org/10.12968/bjon.2016.25 .2 .94 .

Houghton, C.E., Casey, D., Shaw, D., dan Murphy, K. (2012) Staff and students' perceptions and experiences of teaching and assessment in Clinical Skills Laboratories: Interview findings from a multiple case study, Nurse Education Today Journal, 32(6), p e29-e34, doi: https://doi.org/10.1016/j.nedt.2011.10. $\underline{005}$

Houghton, C.E., Casey, D., Shaw, D., dan Murphy, K. (2013) Students' experiences of implementing clinical skills in the real world of practice, Journal of Clinical Nursing, 22(1314), doi: https://doi.org/10.1111/jocn.12014

Kaphagawani, N.C. dan Useh, U. (2017) Analysis of Nursing Students Learning Experiences in Clinical Practice: Literature Review, Studies on Ethno-Medicine Journal, 7 (3), p 181-185, doi: https://doi.org/10.1080/09735070.201 $\underline{3.11886459}$

Llewellyn, D. (2013) Teaching High School Science Through Inquiry and Argumentation Second Edition. California: Corwin.

Meltzer, D. E. (2002). The Relationship between Mathematics Preparation and Conceptual Learning Gains in Physics : A Possible "Hidden Variable" in Diagnostic Pretest Scores. American Association of Physics Teachers, 1259-1268, doi: https://doi.org/10.1119/1.1514215
Nambiar, M., Nedungalaparambil, NM., dan Aslesh, OP. (2016) Is current training in basic and advanced cardiac life support (BLS \& ACLS) effective? A study of BLS \& ACLS knowledge amongst healthcare professionals of North-Kerala, World Journal of Emergency Medicine ,7(4), p 263269. doi: https://doi.org/10.5847/wjem.j.1920$\underline{8642.2016 .04 .004 .}$

Nworgu, L. N., \& Otum, V. V. (2013). Effect of Guided Inquiry with Analogy Instructional Strategy on Students Acquisition of Science Process Skills. Journal of Education and Practice, 4(27), p 35-41. Available at: https://www.iiste.org/Journals/index.p hp/JEP/article/view/9880/10101

Prabowo, C.A., Ibrohim, dan Saptasari, M. (2016) Pengembangan Modul Pembelajaran Inkuiri Berbasis Laboratorium Virtual, Jurnal Pendidikan: Teori, Penelitian, dan Pengembangan, 1(6), p 1090-1097. Available at: http://journal.um.ac.id/index.php/jptp p/article/view/6422/2723

Remziye, Yeter, Sevgül, Zehra, \& Meral (2011) The effects of inquiry-based science teaching on elementary school students' science process skills and science attitudes. Bulgarian Journal of Science and Education Policy (BJSEP), 5(1). Available at: http://seearticles.ceon.rs/data/pdf/13131958/2011/1313-19581101048E.pdf

Rizal. (2014). Pengaruh Pembelajaran Inkuiri Terbimbing dengan Multi Representasi terhadap Keterampilan Proses Sains dan Penguasaan Konsep IPA Siswa SMP. Jurnal Pendidikan Sains, 2(3), p 159-165. Available at: http://journal.um.ac.id/index.php/jptp p/article/view/11747 